\title{
UNCERTAINTY OF EXTREME STORM SURGE ESTIMATION BY HIGH WIND SEA SURFACE DRAG COEFFICIENT AND FUTURE TYPHOON CHANGE
}

\author{
Hiroyasu Kawai ${ }^{1}$, Noriaki Hashimoto ${ }^{2}$, Masaru Yamashiro ${ }^{2}$ and Tomohiro Yasuda ${ }^{3}$
}

\begin{abstract}
Japan has been constructing long coastal defense since the storm surge disaster with a loss of 5,000 lives by Typhoon Vera in 1959. The defense is designed for the storm water level including the storm surge of the standard typhoon based on Typhoon Vera. Stochastic typhoon model, simulating various typhoon track and intensity with Monte Carlo method, is one of useful tools to estimate the return period. According to recent research output the return period of the storm surge of the standard typhoon is near 100 years or more at three major bays in Japan. But there is uncertainty by some of parameters and models in the stochastic simulation. Sea surface drag coefficient under high wind speed and future change in typhoon intensity and track are critical to extreme values of the storm surges.
\end{abstract}

Keywords: stochastic typhoon model; storm surge; design storm water level; return period; sea surface drag coefficient; climate change

\section{INTRODUCTION}

Every year several typhoons make landfall on or pass by the Japanese Islands. Fig.1 shows the coastal line of the Kyushu Island, Shikoku Island, and the southwest part of the Honshu Island. On the Pacific Ocean coast, there are several bays having a length of several ten kilometers from the southern entrance to the northern end. The water depth is shallow less than $30 \mathrm{~m}$ in the majority of the bays. The Japanese three major economical areas, including Tokyo, Nagoya, and Osaka Cities, face such the bays and have a large population and expensive property on wide low-lying land. That is a reason why Japan has the history of terrible storm surge disasters.

The worst storm surge event during the latest 100 years was triggered at Nagoya by Typhoon Vera in 1959. The typhoon made landfall on the Pacific coast of the Hunshu Island with a central pressure of $929 \mathrm{hPa}$ and then passed by Ise Bay. The storm surge reached $3.5 \mathrm{~m}$ at Nagoya on the astronomical tide level of slightly higher than the mean sea level. Consequently coastal defense was breached at many locations and approximately 5,000 people were drawn to death. After the disaster, the Japanese Government determined the standard typhoon with an intensity of Typhoon Vera, simulated the possible maximum storm surge in major bays such as Tokyo Bay, Ise Bay, and Osaka Bay with numerical models, and then defined the design storm water level for coastal defense as the sum of (a) the storm surge by the standard typhoon and (b) the astronomical high tide level. The government also chose the highest storm water level record for the design storm water level on the coast of relatively rural areas. The majority of the concrete coastal defense covering the Japanese coast at the present time is based on the design storm water level. Due to the above-mentioned background most of Japanese coastal engineers believe that such the high storm water level appear very rarely even if it could appear during their lives.

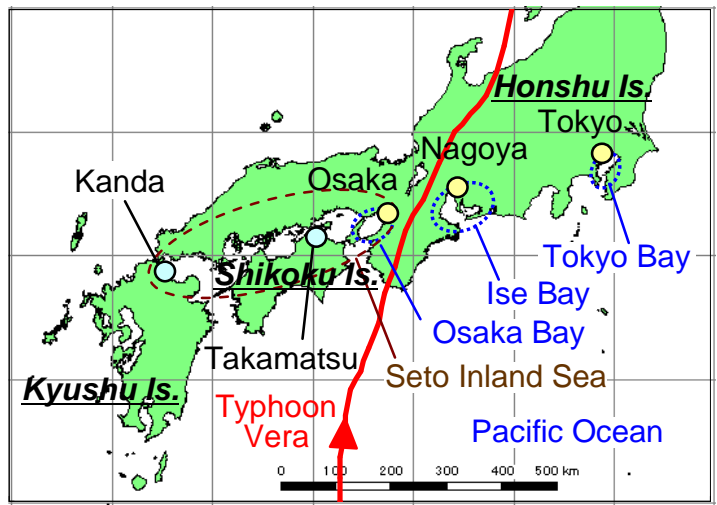

Figure 1. Coastal line of central part of the Japanese Islands with the track of Typhoon Vera

\footnotetext{
${ }^{1}$ Marine Environment and Engineering Department, Port and Airport Research Institute, 3-1-1, Nagase, Yokosuka, Kanagawa, 239-0826, Japan

${ }^{2}$ Faculty of Engineering, Kyushu University, 744, Motooka, Nishi-ku, Fukuoka, Fukuoka, 819-0395, Japan

${ }^{3}$ Research Division for Atmospheric and Hydrospheric Disasters, Disaster Prevention Research Institute, Kyoto University, Gokasho, Uji, Kyoto, 611-0011, Japan
} 
Few efforts have been done in quantification of the return period of the design storm water level.

However, in spite of the coastal defense designed for the high storm water level, severe storm surge disaster was triggered by Typhoon Bart in 1999 (Takahashi et al. 2002, Kawai et al. 2007). Ten typhoons, more than three times the average year, made landfall on the Japanese main four islands and accumulated coastal damage. The time interval between one typhoon and the next was shorter than the recovery. These recent situations let the engineers recognize that the estimation of the return period of the current design storm water level is necessary for the performance evaluation of the coastal defense.

\section{STOCHASTIC SIMULATION AND RECENT RESEARCH OUTPUT}

\section{Recent Research with Stochastic Simulation}

The most reliable and direct estimation of the return period of the current design storm water level is the extreme-value analysis on water level data obtained at a tide station for a certain long period. But the history of tide observation is still short in Japan except for a few tide stations. Comparing that the storm surge magnitude varies even in a small bay, the density of tide stations may be insufficient. Therefore we need to collect the water level data by the other method. A stochastic simulation, which is the combination of

- the stochastic typhoon simulation providing the track and intensity of numerous typhoons by the Monte Carlo model based on past typhoon statistics (Hashino and Kuwata 1987, Hatada and Yamaguchi 1996, Katoh et al. 2003, Rumpf et al. 2006),

- the calculation of the storm surge of each typhoon, and

- the fitting of the storm surges to an extreme-value function,

is one of useful tools to breakthrough the above-mentioned difficulty. Fig.2 illustrates the concept of the stochastic simulation. There are several stochastic typhoon models.

Fig. 3 shows an example of the recent research outputs (Kawai et al. 2008a, 2008b). The storm surge by the standard typhoon and its return period is $3 \mathrm{~m}$ and 1,500 years respectively at Tokyo, $3.5 \mathrm{~m}$ and 150 years at Nagoya, and then $3 \mathrm{~m}$ and 100 years at Osaka. The current design storm water level including the astronomical high tide level and its return period is $5.1 \mathrm{~m}$ and much longer than 1,000 years respectively at Tokyo, $5.9 \mathrm{~m}$ and 400 years at Nagoya, and then $4.8 \mathrm{~m}$ and 250 years at Osaka. These results show that the current design storm water level is not so low in engineering sense. However, we need to take care of the uncertainty in the stochastic simulation for quantitatively detailed discussion on the safety degree of coastal defense. Actually some of the parameters and models in the simulation, such as the number of the typhoon samples and the distortion of the typhoon pressure distribution, affect the extreme wave and storm surge values (Yamaguchi et al. 1995, Nonaka et al. 2000). Then this study focused on (1) the typhoon wind field estimated with empirical models, (2) the sea surface drag coefficient under very high wind speed of more than $30 \mathrm{~m} / \mathrm{s}$, and (3) future typhoon change.

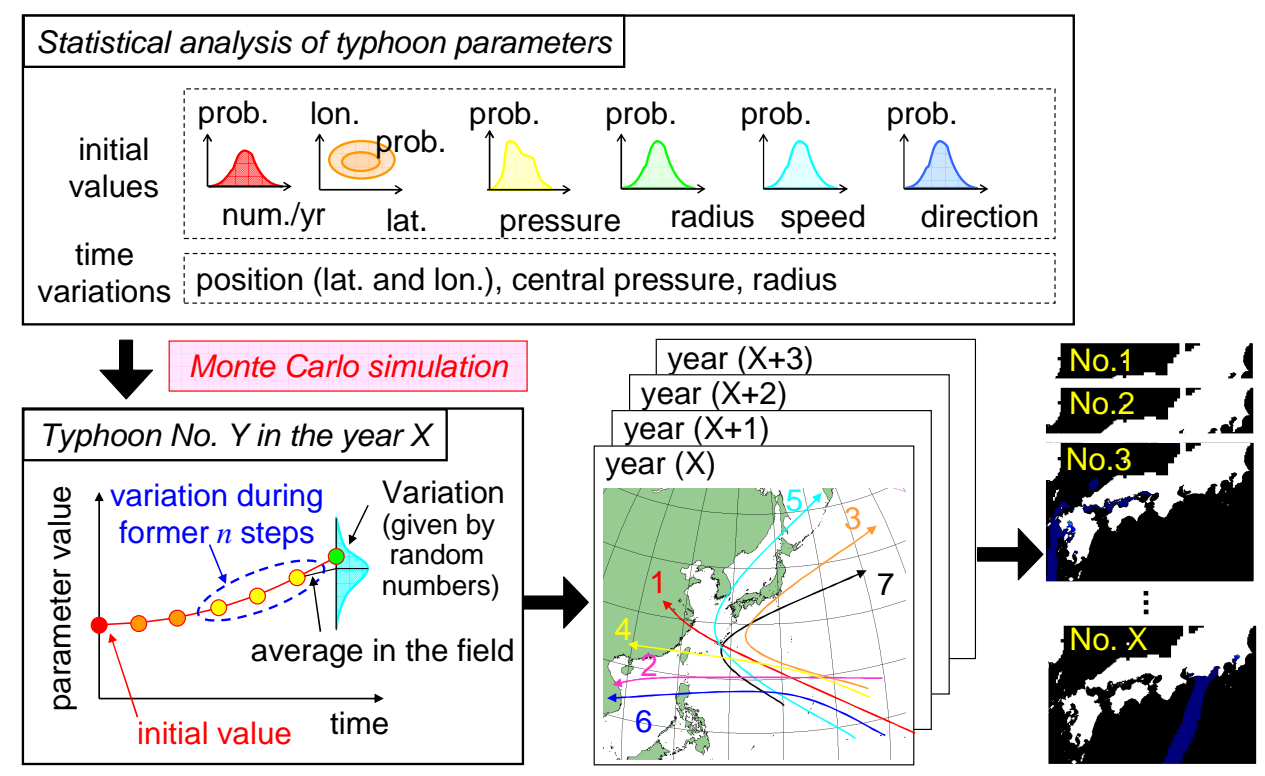

Figure 2. Concept of stochastic simulation 


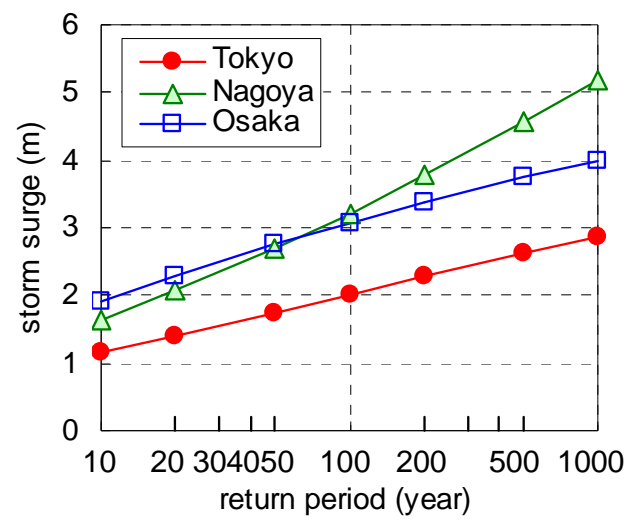

(a) storm surge

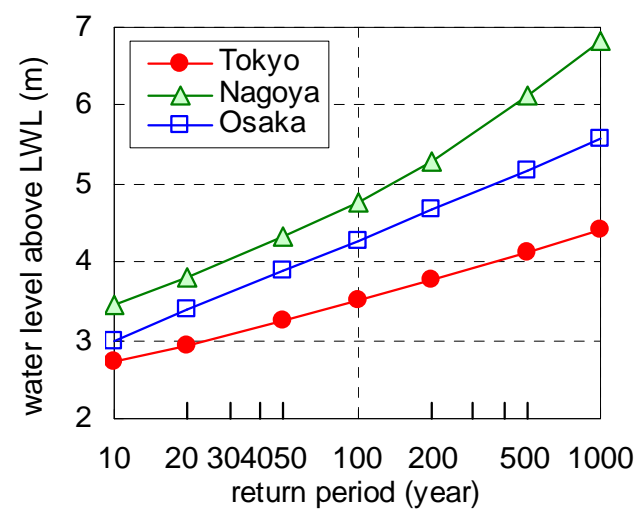

(b) water level (=astronomical tide + storm surge)

Figure 3. Storm surge and water level with a return period of 10 to 1000 years at major locations.

\section{Stochastic Typhoon Model and Future Typhoon Change}

Among several research on stochastic typhoon models, Hashimoto et al. (2004) divided typhoons affecting Japan from 1951 to 1999 into five seasons, (a) June and July, (b) August, (c) September, (d) October, and (e) other months, and estimated the parameters, (a) the location of the typhoon center, (b) the central pressure, (c) the radius of maximum wind speed, and their variation with time, in each season in each rectangular cell with a width of 1.5 degrees in longitude and a height of 1.5 degrees in latitude. On this analysis, the radius of maximum wind speed of each typhoon was estimated from the central pressure and the radius of a constant pressure contour on weather maps, provided from the Japan Meteorological Agency. Then they developed an auto-regression model to describe the variation of each parameter with time of each typhoon.

$$
T_{i}=T_{i-1}+\Delta T_{i}=T_{i-1}+S\left(x_{i}, y_{i}\right)+\sum_{m=1}^{n} A_{m} Z_{i-m}+v_{i}
$$

Hence, $i$ is the time step with an interval of one hour, $T_{i}$ is the parameter value, $\Delta T_{i}$ is the variation of the value per hour, $S\left(x_{i}, y_{i}\right)$ is the mean variation at the longitude $x_{i}$ and the latitude $y_{i}, A_{m}$ is the autoregressional coefficient determined by Akaike's Information Criteria, $Z_{i-m}$ is the deviation, and then $v_{i}$ is the white noise. This paper gave numerous typhoons under the current climate by the above-mentioned stochastic typhoon model (hereinafter STM-p).

According to recent meteorological research on future climate in the northwest Pacific region, typhoon intensity may increase on the average while severe typhoon frequency may decrease (Oouchi et al. 2006). A quantitatively projection of the frequency, track, and intensity of future typhoons is still quite difficult due to the uncertainty in the numerical model and its input data, while qualitatively rough estimation may be possible at the present time. That is a reason why this paper examined two stochastic typhoon models with a simple future change in typhoon characteristics. The first model (hereinafter STM-n) assumes that the filed $S\left(x_{i}, y_{i}\right)$ will move toward north by 1.5 degrees in longitude and that the probability distribution of the typhoon origin will not change (Kawai et al. 2006). It means that the typhoon developing area will expand toward the north and that the frequency of intense typhoons will increase at high latitude. The second model (hereinafter STM-i) assumes a simple change that the central pressure depression will increase by $10 \%$ for all the typhoons in all the area.

This paper conducted the above-mentioned the stochastic typhoon model STM-p for the current climate and two stochastic typhoon models STM-n and STM-i for the future climate, to provide the parameters of the typhoons for 500 years respectively. And then this paper picked up major typhoons crossing the target area with a certain low central pressure to reduce the quantity of storm surge simulation. The number of finally selected typhoons is 1,301 for STM-p and STM-i and is 1,399 for STM-n.

\section{Typhoon Wind Field Model}

The marine surface pressure field $p(r)$ of each typhoon at each time step was given in this paper with Myer's equation (1961) that is one of the most popular empirical parametric models:

$$
p(r)=p_{c}+\Delta p \exp \left(-r_{0} / r\right)
$$


where $r$ is the radial distance from the typhoon center, $p_{c}$ is the central pressure, $\Delta p$ is the difference between the central pressure and the environmental pressure, and then $r_{0}$ is the radius of maximum wind speed. The location and central pressure were given by the stochastic typhoon model.

The marine surface wind field is estimated from the pressure field and the typhoon forwarding speed. This paper compared two different wind fields given by empirical parametric models. The first model (hereinafter Typ1) gives the sum of the vectors of the pressure gradient wind and the typhoon forwarding effect. The pressure gradient wind component $U_{1}$ can be estimated from the balance of the pressure gradient force, the Coriolis force, and the centrifugal force at a wind element on a constant pressure contour.

$$
U_{1}(r)=C_{1} U_{g r}(r)=C_{1}\left\{-\frac{r f}{2}+\sqrt{\left(\frac{r f}{2}\right)^{2}+\frac{\Delta p}{\rho_{a}} \frac{r_{0}}{r} \exp \left(-\frac{r_{0}}{r}\right)}\right\}
$$

The typhoon forwarding component $U_{2}$ is proportional to the forwarding speed.

$$
U_{2}=C_{2}\left(U_{1} / U_{1, r 0}\right) V_{T}
$$

where $C_{1}$ and $C_{2}$ are wind speed reduction factors (0.66 in this paper), $f$ is the Coriolis parameter, $\rho_{a}$ is the density of the air, $U_{1, r 0}$ is the wind speed $U_{1}$ at $r=r_{0}$, and then $V_{T}$ is typhoon forwarding speed. The direction of the pressure gradient wind component is 30 degree inward due to sea surface friction. Fig. 4 shows the wind field with $p_{c}=940 \mathrm{hPa}, r_{0}=75 \mathrm{~km}, V_{T}=70 \mathrm{~km} / \mathrm{hr}$ where the maximum wind speed appears to the southeast from the typhoon center. This model is very popular in practical works in Japan and was often used in previous stochastic typhoon and storm surge simulations (Kawai et al. 2006, 2007, 2008a, 2008b).

The second model (hereinafter Typ2) gives the solution of the balance equation of typhoon forwarding effect as well as the pressure gradient force, the Coriolis force, and the centrifugal force. The wind speed $W$ is given by

$$
\begin{gathered}
W=C\left\{-\frac{r f-V_{T} \sin \beta}{2}+\sqrt{\left(\frac{r f-V_{T} \sin \beta}{2}\right)^{2}+\frac{\Delta p}{\rho_{a}} \frac{r_{0}}{r} \exp \left(-\frac{r_{0}}{r}\right)}\right\} \\
C=C_{\infty}+\left(C_{p}-C_{\infty}\right)\left(\frac{X}{X_{p}}\right)^{k-1} \exp \left\{\left(1-\frac{1}{k}\right)\left[1-\left(\frac{X}{X_{p}}\right)^{k}\right]\right\} \\
C_{p}=\min \left\{\frac{2}{3}\left[1+10^{(0.0231 \Delta p-1.95)}\right], 1\right\}
\end{gathered}
$$

where $\beta$ is the direction from the typhoon center, $C_{\infty}=2 / 3, k=2.5, X=r / r_{0}$, and $X_{p}=1 / 2$. The wind speed reduction ratio $C$ considers super gradient wind of which direction is given as a function of the radial distance (Mitsuta and Fujii, 1987). This paper introduced a limitation of 1 in the parameter $C_{p}$ to avoid unrealistic intense wind speed. Fig. 4 shows the wind filed calculated by the model Typ 2 with the same parameters as Typ1. This model gives the maximum wind speed to the east of the typhoon center.

Fig. 5 compares the variation of the wind speed at Kanda, locating at the west end of Seto Inland Sea (see Fig.1), during the passage of Typhoon Chaba, T0416, estimated by the empirical parametric

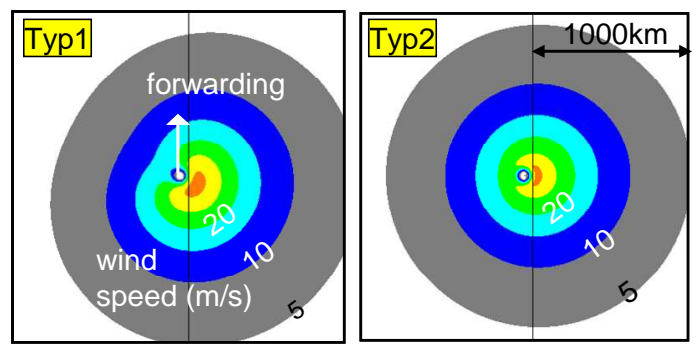

Figure 4. Wind field calculated by empirical models 


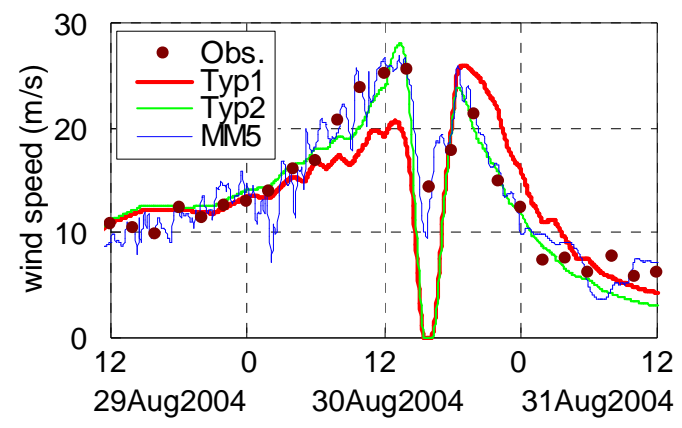

Figure 5. Comparison of wind speed

models Typ1 and Typ2 and the meso-scale physical model MM5 (Kawai et al. 2009). Among three models, the model MM5 looks most precise, and the model Typ2 is better than the model Typ1.

\section{Storm Surge Model and Sea Surface Drag Coefficient}

The storm surge is computed by a typical one-layer non-linear long wave model (Kawai and Takemura, 2002) based on the following governing equations:

$$
\begin{gathered}
\frac{d \eta}{d t}+\frac{\partial M}{\partial x}+\frac{\partial N}{\partial y}=0 \\
\frac{\partial M}{\partial t}+\frac{\partial}{\partial x}\left(\frac{M^{2}}{D}\right)+\frac{\partial}{\partial y}\left(\frac{M N}{D}\right)=f N-g D \frac{\partial \eta}{\partial x}-\frac{D}{\rho_{w}} \frac{\partial p}{\partial x}+\frac{\tau_{s x}-\tau_{b x}}{\rho_{w}}+A_{h}\left(\frac{\partial^{2} M}{\partial x^{2}}+\frac{\partial^{2} M}{\partial y^{2}}\right) \\
\frac{\partial N}{\partial t}+\frac{\partial}{\partial x}\left(\frac{M N}{D}\right)+\frac{\partial}{\partial y}\left(\frac{N^{2}}{D}\right)=-f M-g D \frac{\partial \eta}{\partial y}-\frac{D}{\rho_{w}} \frac{\partial p}{\partial y}+\frac{\tau_{s y}-\tau_{b y}}{\rho_{w}}+A_{h}\left(\frac{\partial^{2} N}{\partial x^{2}}+\frac{\partial^{2} N}{\partial y^{2}}\right)
\end{gathered}
$$

where $M$ and $N$ is the $x$ and $y$ component of the flux flow respectively, $\eta$ is the water surface elevation, $D$ is the total depth, $\rho_{W}$ is the density of sea water, $\tau_{s x}$ and $\tau_{s y}$ is the $x$ and $y$ component respectively of the sea surface stress, $\tau_{b x}$ and $\tau_{b y}$ is the $x$ and $y$ component respectively of the sea bottom stress with Manning's roughness coefficient, and then $A_{h}$ is the horizontal eddy diffusion coefficient. The sea surface stress is given by

$$
\begin{aligned}
& \tau_{s x}=\rho_{a} C_{d} W_{x} \sqrt{W_{x}^{2}+W_{y}^{2}} \\
& \tau_{s y}=\rho_{a} C_{d} W_{y} \sqrt{W_{x}^{2}+W_{y}^{2}}
\end{aligned}
$$

where $C_{d}$ is the sea surface drag coefficient. Mitsuyasu and Kusaba's drag coefficient (1984),

$$
C_{d}= \begin{cases}(1.290-0.024 W) / 10^{3} & (W<8) \\ (0.581+0.063 W) / 10^{3} & (W \geq 8)\end{cases}
$$

is widely used for the storm surge simulation in Japan. Fig. 6 shows the coefficient in a graph. The model assumes that the coefficient is proportional to the wind speed when the wind speed is larger than $8 \mathrm{~m} / \mathrm{s}$. However, recent research showed that the value may be constant or decrease for a very high wind speed such as $30 \mathrm{~m} / \mathrm{s}$ (Powell et al. 2003, Zhang et al. 2006). Therefore this study examined the coefficient $C_{d l m t}$, being constant for more than $30 \mathrm{~m} / \mathrm{s}$ and the moderate coefficient $C_{d r d}$ between $C_{d}$ and $C_{d l m t}$. The storm surge model conducted in this study is not coupled with a wave model. The complicated process is not included how much wave splays enforces storm surges under high wind condition. If such the phenomenon is predominant, we should take a larger sea surface drag coefficient to count the effect in the simple storm surge model.

The target area in this paper is the semi-closed bays with large population and expensive property, such as Tokyo Bay, Ise Bay, and Seto Inland Sea including Osaka Bay. Fig. 7 shows the computational domain with a spatial grid interval of $1.8 \mathrm{~km}$. The storm surge model uses two-way nested grids. The 


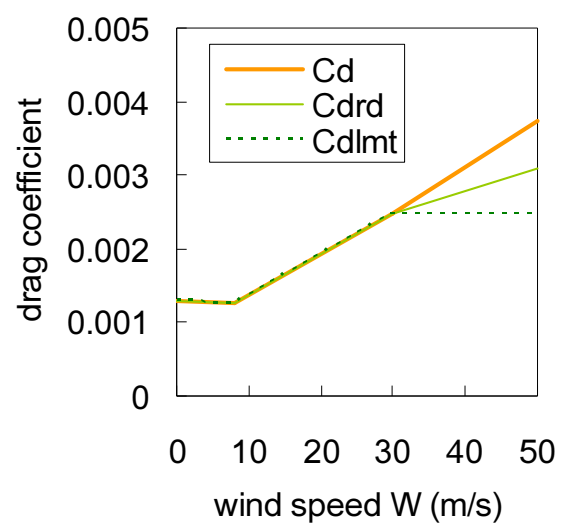

Figure 6. Sea surface drag coefficient examined in this study

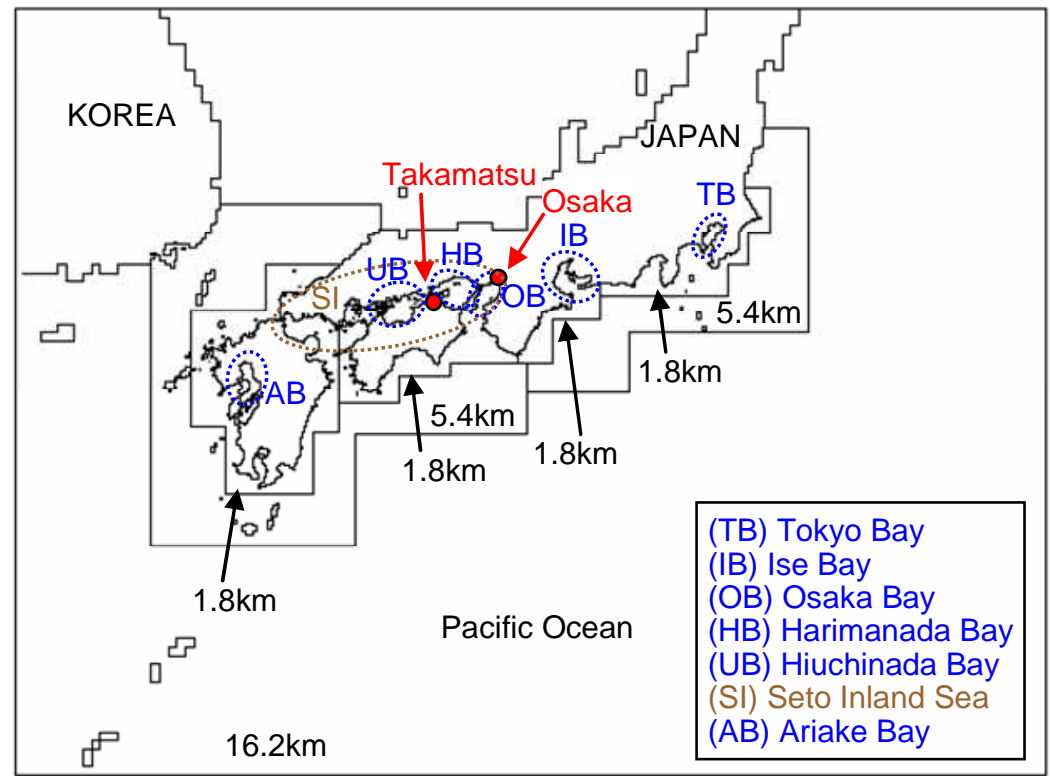

Figure 7. Computational domain for storm surge simulation

storm surge model does not include terms for wave setup in the governing equations but is applicable for these bays because the wind wave height is much lower in these bays than on the open coast for the Pacific Ocean.

\section{Extreme-value Analysis}

Following the storm surge simulation, the best-fitting extreme value function of the storm surges was selected from the Gumbel (FT-I) Distribution, the FT-II Distribution with a shape parameter $k=2.5$, $3.33,5$, and 10, and the Weibull Distribution with $k=0.75,1,1.4$, and 2. The most applicable distribution was selected among these nine ones. And then the extreme storm surge with a return period of 10 to 1,000 years was estimated at each computational grid on Fig. 7. Consequently the Weibull Distribution ( $k=1.4$ or 2.0) was selected at the majority of the grids and the Gumbel Distribution or the FT-II Distribution $(k=10)$ at some other grids for the case of the model STM-p and the coefficient $C_{d}$.

\section{UNCERTAINTY IN STOCHASTIC SIMULATION}

\section{Comparison by Wind Field Model}

As mentioned in the former chapter, there are two typical wind field models Typ1 and Typ2. The model Typ1 was often used in the stochastic simulation, but the model Typ2 gives a better wind field than the model Typ1. That is reason why this paper compares the storm surge estimated by the model Ty2 with that by the model Typ1. 
Fig. 8 shows the storm surges of the stochastic typhoons during 500 years at two typical locations, Osaka and Takamatsu. In this comparison, the common typhoons provided by the stochastic typhoon model STM-p were examined and the common sea surface drag coefficient $C_{d}$ was selected in the storm surge calculation. At Osaka, 5 typhoons with a storm surge of more than $3 \mathrm{~m}$ appeared in each case. The difference from the storm surge calculated by the model Typ 2 to that by the model Typ 1 is large if the storm surge is larger than $2 \mathrm{~m}$. The mean ratio of the storm surge calculated by the model Typ 2 on that by the model Typ 1 is 0.87 . On the other hand, at Takamatsu, the difference in the storm surge between the models Typ 1 and Typ2 is small and the mean ratio of the storm surge calculated by the model Typ2 on the model Typ1 is 0.99 . Such the difference in the bias of the storm surges between two locations may be related with the difference in the predominant component of the storm surge. Actually Osaka locates at the innermost of Osaka Bay where the wind-drift effect on the storm surge is generally much larger than the suction effect of depression. Takamatsu locates near the water strait connecting Harimanada Bay with Hiuchinada Bay where the wind-drift effect is smaller than Osaka.

Fig. 9 compares the extreme-value functions of the storm surges between the models Typ1 and Typ2. The extreme-value of the storm surges estimated by the model Typ2 is smaller than that with th model Typ1 until the return period of 500 and 300 years at Osaka and Takamatsu respectively. But the relation will reverse at a longer return period.

Fig. 10 compares the plane distribution of the 100-year-return storm surge estimated by the models Typ1 and Typ2. In both the models the extreme-value of the storm surges is large in several bays such as Tokyo Bay, Ise Bay, Seto Inland Sea, and Ariake Bay. Comparing these models more carefully, the storm surge calculated by the model Typ2 is smaller than that with the model Typ1 in the eastern and central part of Seto Inland Sea and is larger in the west part of Seto Inland Sea, Tokyo Bay, Ise Bay and

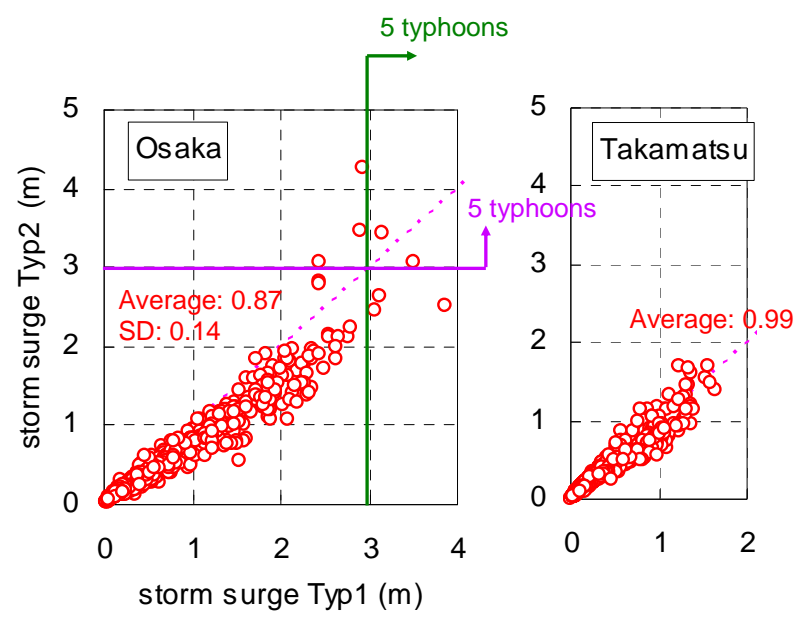

Figure 8. Comparison of storm surges between Typ1 and Typ2

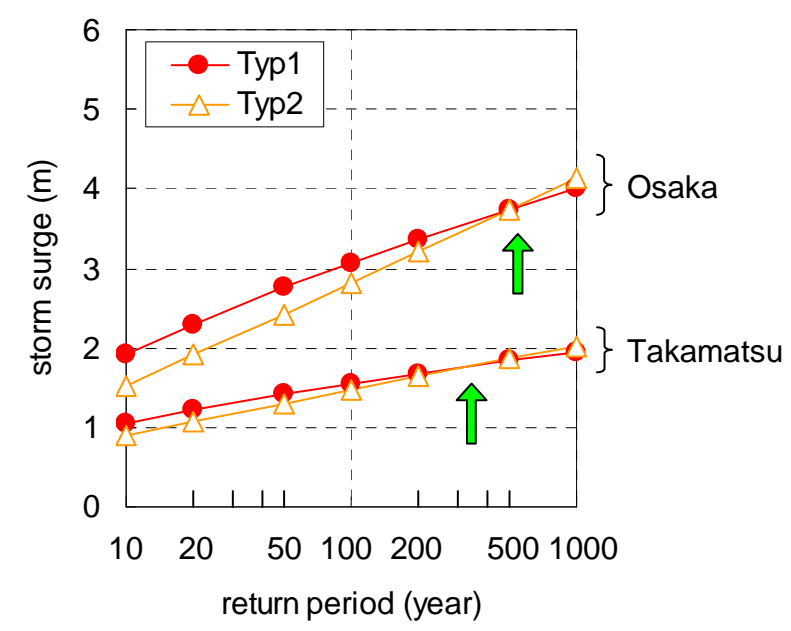

Figure 9. Comparison of extreme value functions between Typ1 and Typ2 

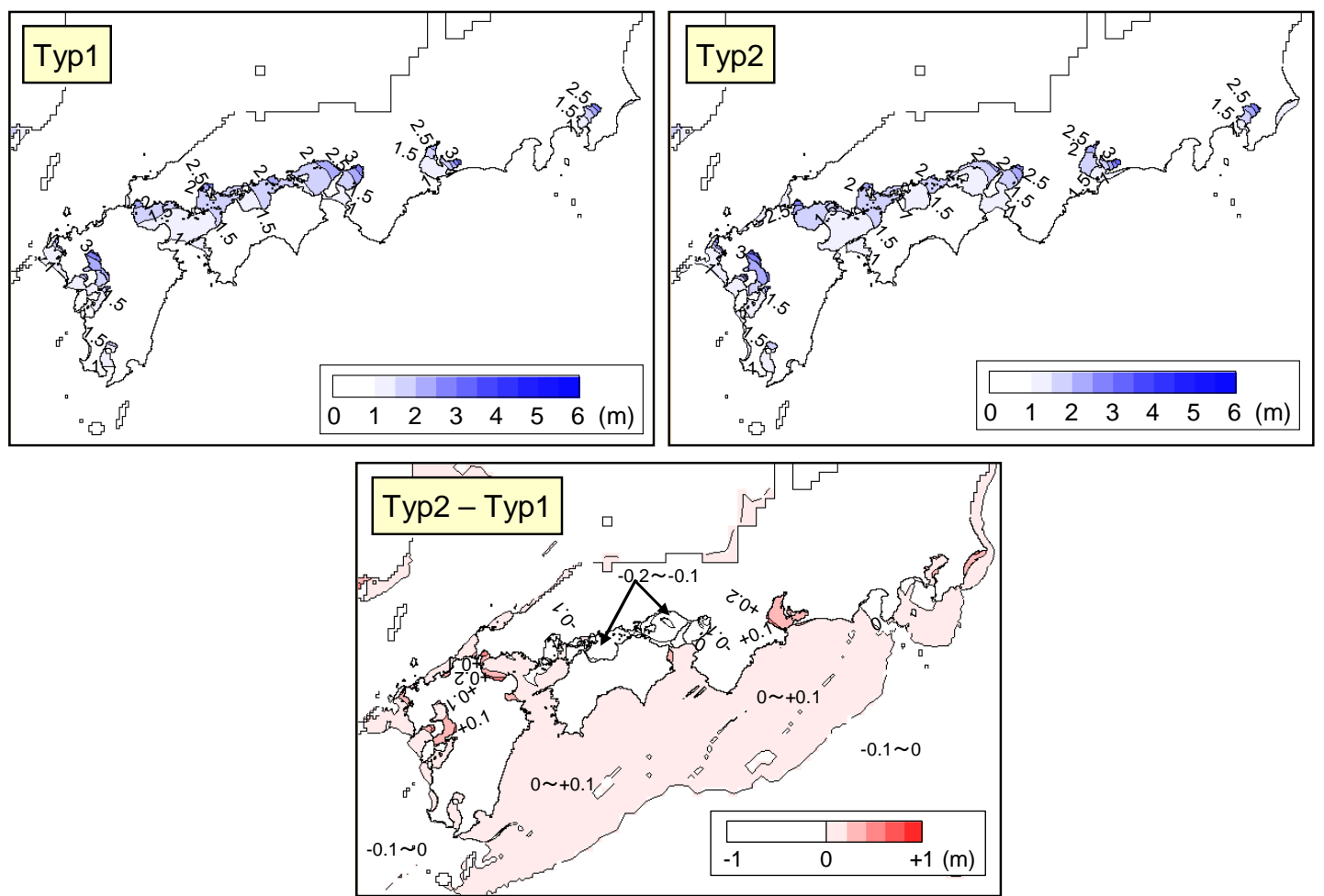

Figure 10. Comparison of 100-year-return storm surge distributions between Typ1 and Typ2
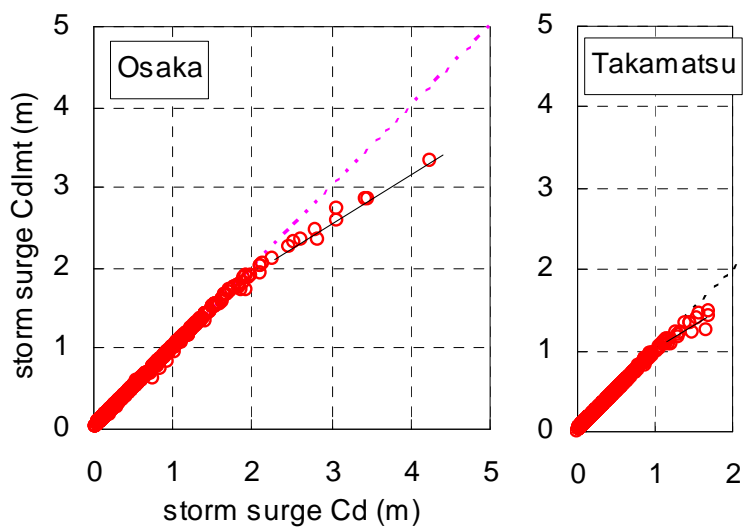

Figure 11. Comparison of storm surges between $\mathrm{Cd}$ and CdImt

Ariake Bay. Such the bias in the extreme-value may be related with the difference in the position of the maximum wind speed in a typhoon (see Fig.4).

\section{Comparison by Sea Surface Drag Coefficient}

According to recent research on stochastic simulation, the return period of the storm surge of the current standard typhoon is nearly 100 years or more at three major bays, Tokyo Bay, Ise Bay, and Osaka Bay (Kawai et al. 2008a, 2008b). The drag coefficient plays a very important role in the storm surge simulation for an intense typhoon having a high wind speed such as more than $30 \mathrm{~m} / \mathrm{s}$. That is reason why the effect of the sea surface drag coefficient on the storm surge should be verified.

Fig. 11 shows the storm surges of the stochastic typhoons, estimated with the sea surface drag coefficients $C_{d}$ and $C_{d l m t}$. The common stochastic typhoon model STM-p and wind field model Typ2 were selected in this comparison. At Osaka, the difference from the storm surge calculated with the coefficient $C_{d l m t}$ to that with the coefficient $C_{d l m t}$ appears at the storm surge of $2 \mathrm{~m}$. The difference reaches approximately $0.3 \mathrm{~m}$, being equivalent to $10 \%$, at the storm surge of $3 \mathrm{~m}$. At Takamatsu, the difference appears at the storm surge of $1 \mathrm{~m}$. 


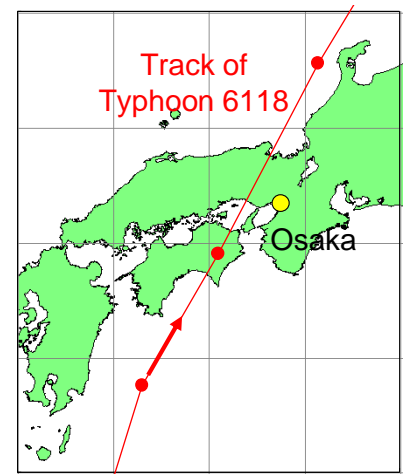

Figure 12. Track of Typhoon Nancy

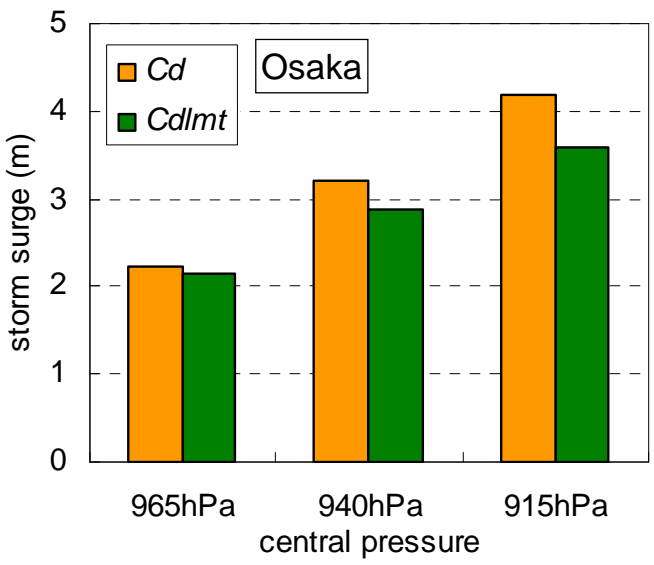

Figure 13. Comparison of storm surges at Osaka

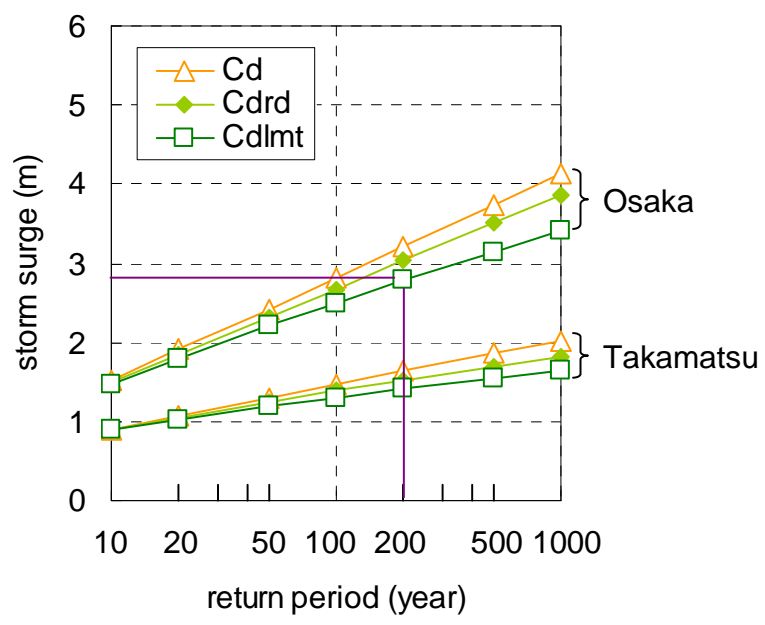

Figure 14. Comparison of extreme value functions between $\mathrm{Cd}$ and $\mathrm{CdImt}$

On the other hand, Fig. 12 shows the tack of Typhoon Nancy, T6118, of which track is similar to the current standard typhoon and Fig. 13 shows the storm surge at Osaka by the typhoon tracing the track of Typhoon Nancy with a central pressure of 965,940 , and $915 \mathrm{hPa}$. The difference of the storm surge estimated with the coefficient $C_{d l m t}$ from that with the coefficient $C_{d l m t}$ is very small for the typhoon with a central pressure of $965 \mathrm{hPa}$ near the intensity of a decadal typhoon. The difference is still not so large for the typhoon with a central pressure of $940 \mathrm{hPa}$, near the intensity of the current standard typhoon, and is large for the typhoon with a central pressure of $915 \mathrm{hPa}$, over the intensity of the current standard typhoon.

Fig. 14 compares the extreme-value functions of the storm surges estimated with the coefficients $C_{d}$ and $C_{d l m t}$. The difference in the extreme-value of the storm surges is small at a return period of 10 years, but increases rapidly at a longer return period. For example at Osaka, the 100-year-return storm surge estimated with the coefficient $C_{d}$ is nearly equal to the 200-year-return storm surge with the coefficient $C_{d l m t}$.

Fig. 15 compares the plane distributions of the 100-year-return storm surge between the coefficients $C_{d}$ and $C_{d l m t}$. In both the cases, the 100-year-return storm surge is large in several bays such as Tokyo Bay, Ise Bay, Seto Inland Sea, and Ariake Bay. The difference of the storm surge estimated with the coefficient $C_{d l m t}$ from that with the coefficient $C_{d}$ is negative at all the bays and is significant at the innermost of the bays where storm surge often becomes significant. 

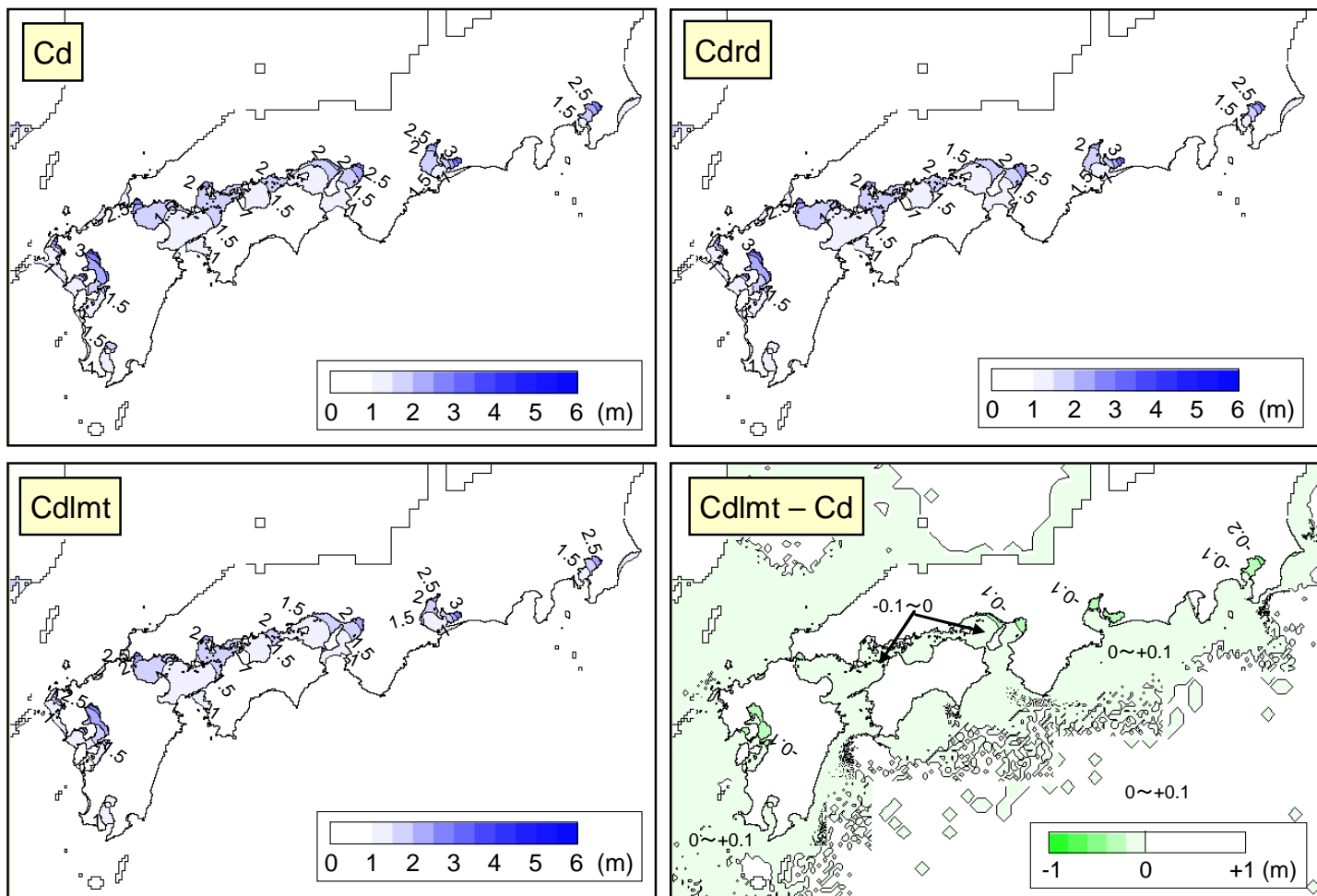

Figure 15. Comparison of 100-year-return storm surge distributions between $\mathrm{Cd}$ and $\mathrm{Cdlmt}$

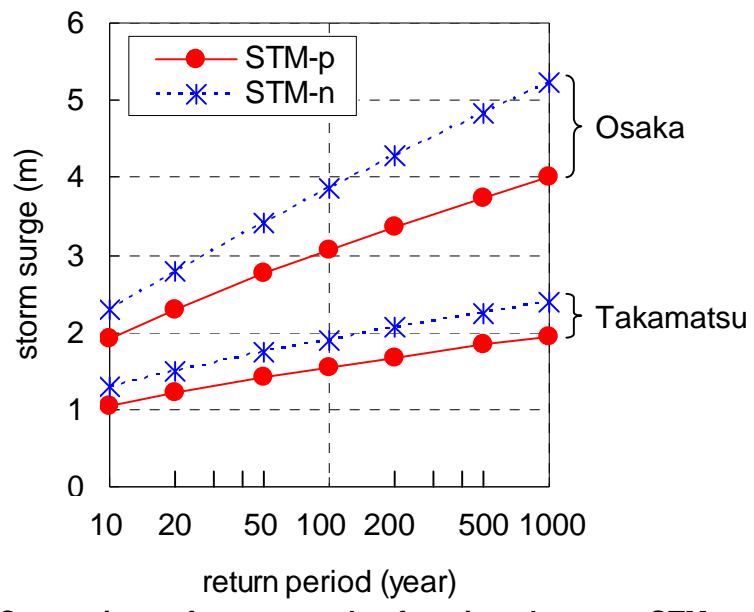

Figure 16. Comparison of extreme value functions between STM-p and STM-n

\section{Comparison by Future Typhoon Change}

The return period of the storm surge of the current standard typhoon decreases if intense typhoons will appear frequently. This paper assumes two simple scenarios of future typhoon change although precise future climate change simulation is still quite difficult.

Fig. 16 compares the extreme-value functions of the storm surges between the stochastic typhoon models STM-p and STM-n. The model STM-p was developed based on the past typhoon statistics while the model STM-n assumes that the plane distribution of the mean variation of the typhoon parameter with time $\Delta S\left(x_{i}, y_{i}\right)$ moves toward to north by 1.5 degree on latitude. There is a large difference in the storm surge between these cases even for a short return period at Osaka. Fig. 17 compares the plane distribution of the 100-year-return storm surge. The areas with a large 100-year-return storm surge are common between these cases. Comparing more carefully, the model STM-n gives a larger 100 -year-retunr storm surge in whole of Seto Inland Sea and Ariake Bay, and gives a smaller storm 

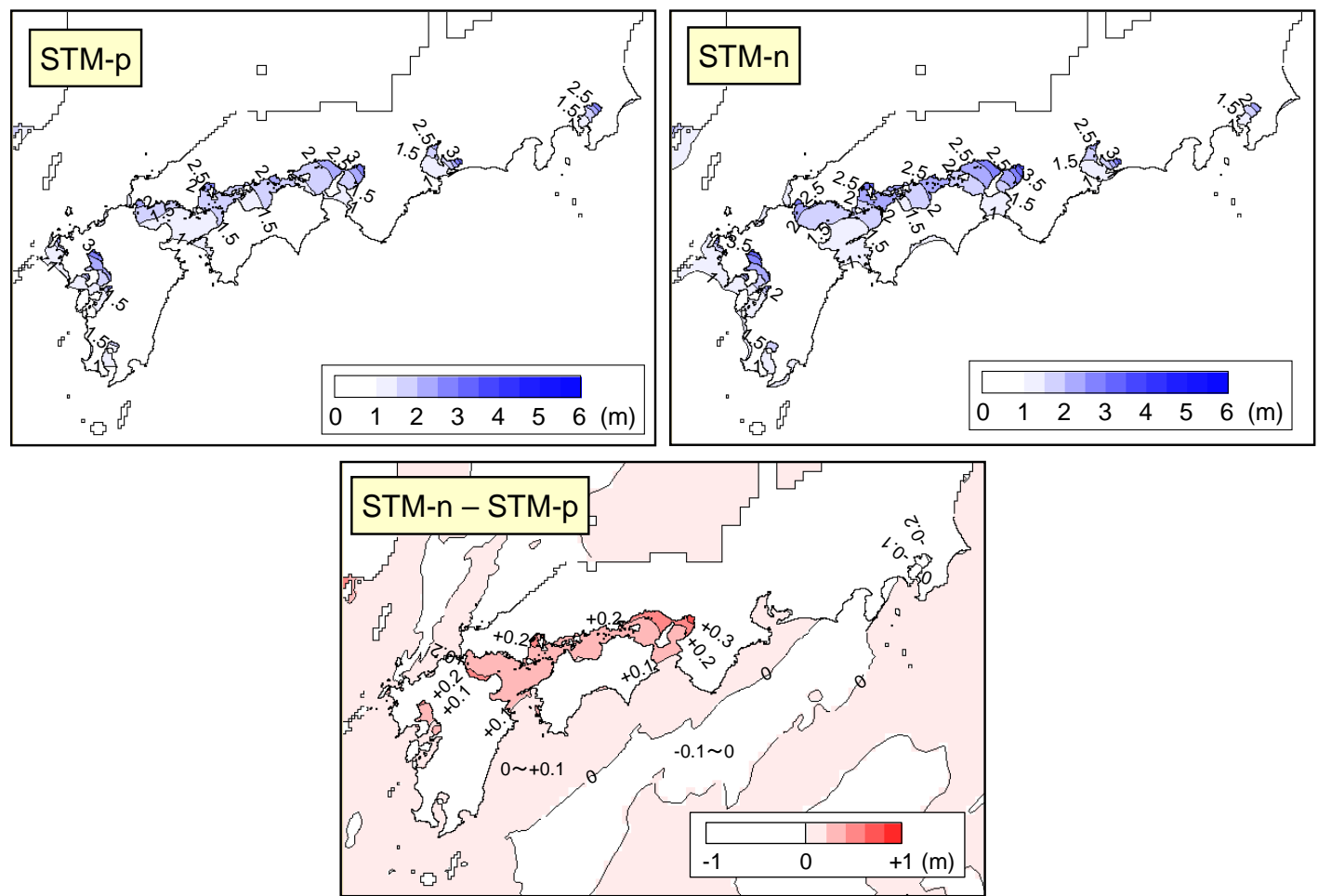

Figure 17. Comparison of 100-year-return storm surge distributions between STM-n and STM-p

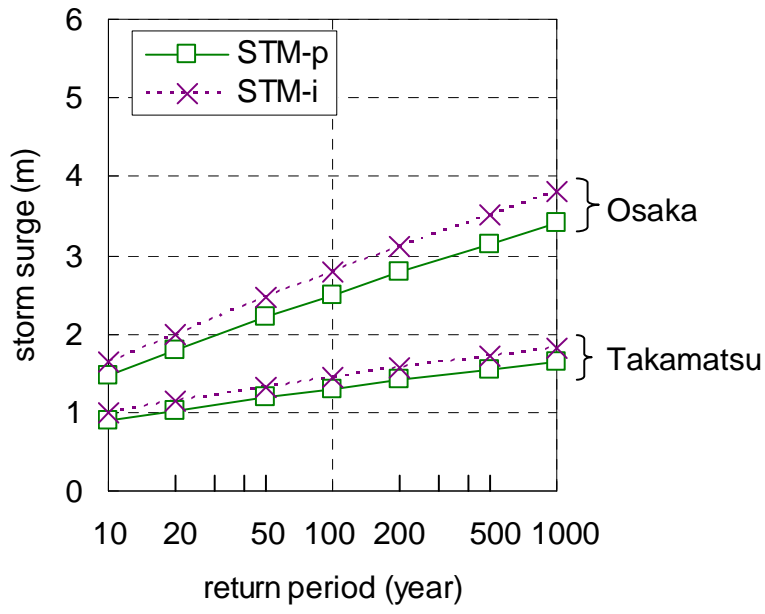

Figure 18. Comparison of extreme value functions between STM-p and STM-i

surge in limited areas including Tokyo Bay. The result leads that the storm surge is very sensitive to the change in typhoon track and intensity.

On the other hand, Fig. 18 compares the extreme-value functions of the storm surges between the stochastic typhoon models STM-p and STM-i. The model STM-i assumes the typhoon intensification by $10 \%$. The wind field model Typ 2 and the sea surface drag coefficient $C_{d l m t}$ were commonly selected in these cases. The difference of the extreme-value of the storm surges estimated by the model STM-i from that with the model STM-i is large at a long return period. Figure 19 compares the plane distributions of the 100-year-return storm surge between these cases. The areas with a large 100-year-return storm surge are common between these cases, and the difference is large in areas with a large 100-yearreturn storm surge. 

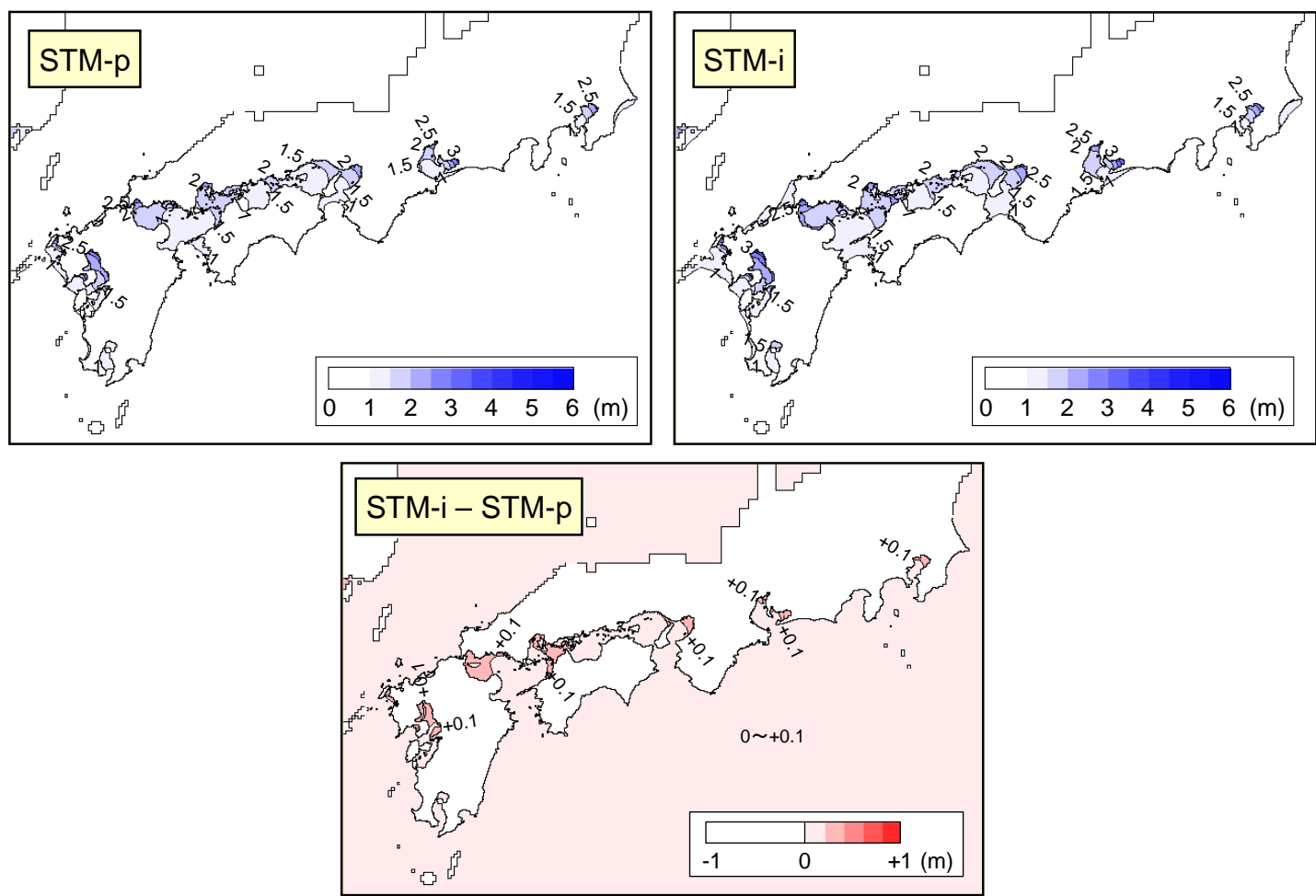

Figure 19. Comparison of 100-year-return storm surge distributions between STM-p and STM-i

\section{CONCLUDING REMARKS}

Stochastic simulation is one of useful tools to identify the return period of the current storm water level based on Typhoon Vera in 1959. However, there is uncertainty in some of the parameters and models in the simulation. That is a reason why we conducted the sensitivity analysis on (a) the empirical parametric marine surface wind field model, (b) the sea surface drag coefficient under high wind speed, and (c) the future typhoon change. The analysis led the following results:

(1) The extreme-value of the storm surges is large at innermost regions of several bays on the Pacific Coast of Japan, in any wind field model, sea surface drag coefficient, and future typhoon change within the assumptions in this paper.

(2) The extreme-value of the storm surge is sensitive at these regions to the wind field model, sea surface drag coefficient, and future typhoon change. The sea surface drag coefficient is a critical parameter to identify the long return period of the current storm water level based on the standard typhoon and discuss on the possibility of higher water level than the design. One of two scenarios on the future typhoon change in this paper gave the decrease in the extreme-value of the storm surge in some of the regions.

We would like to introduce more precise model with more appropriate parameters into the stochastic simulation with care of the uncertainty in the simulation. Such the efforts are necessary for the performance evaluation of coastal defense at present time and in the future.

\section{ACKNOWLEDGMENTS}

This study was supported by KAKENHI 20360220, Japan Society for the Promotion of Science.

\section{REFERENCES}

Hashino, M. and Y. Kuwata. 1987. Evaluation of concurrent characteristics of rainfall and storm surge by a stochastic typhoon model, Journal of Natural Disaster Science, Vol.9, No.1, pp 79-97.

Hashimoto, N., H. Kawai and K. Matsuura. 2004. Development of stochastic typhoon model for performance design of coastal structures, Proceedings of $29^{\text {th }}$ International Conference on Coastal Engineering, ASCE, Melbourne, Australia, pp 3615-3627. 
Hatada, Y. and M. Yamaguchi. 1996. A Stochastic Typhoon Model and its Application to the Estimation of Storm Surge and Wave Height, Proceedings of $25^{\text {th }}$ International Conference on Coastal Engineering, ASCE, Vol 2, pp 1389-1402.

Kato, F., K. Torii, H. Shibaki and K. Suzuyama. 2003. Probabilistic estimation of tide levels and wave overtopping rates using a stochastic typhoon model, Proceedings of Coastal Engineering, JSCE, vol.50, pp.291-295, in Japanese.

Kawai, H. and S. Takemura. 2002. Simultaneity of maximum storm surge and wave caused by typhoon in Tokyo Bay, Japan, Proceedings of $28^{\text {th }}$ International Conference on Coastal Engineering (ICCE2002), ASCE, Vol 1, pp 1216-1228.

Kawai, H., N. Hashimoto and K. Matsuura. 2006. Improvement of stochastic typhoon model for the purpose of simulating typhoons and storm surges under global warming, Proceedings of $30^{\text {th }}$ International Conference on Coastal Engineering (ICCE2006), ASCE, San Diego, USA, Vol 2, pp 1838-1850.

Kawai, H., S. Takahashi, T. Hiraishi, N. Hashimoto and K. Matsuura. 2007. Lessons learned from recent storm surge disasters and estimation of extreme tidal levels for coastal defense performance by using stochastic typhoon model, Proceedings of $17^{\text {th }}$ (2007) International Ocean and Polar Engineering Conference, ISOPE, Vol 3, pp 1792-1799.

Kawai, H., N. Hashimoto and K. Matsuura. 2008a. Estimation of extreme storm water level in Japanese bays by using stochastic typhoon model and tide observation data, Proceedings of the $18^{\text {th }}$ (2008) International Offshore and Polar Engineering Conference, ISOPE, Vol.3, pp.543-550.

Kawai, H., N. Hashimoto and K. Matsuura. 2008b. Estimation of extreme storm surge and its duration in Japanese bays by using stochastic typhoon model, Proceedings of the $31^{\text {st }}$ International Conference on Coastal Engineering (Poster-paper), ASCE.

Kawai, H.., N. Hashimoto and M. Yamashiro. 2009. Real-time Probabilistic Prediction of storm water level at Japanese ports, Proceedings of the $19^{\text {th }}$ (2009) International Offshore and Polar Engineering Conference, ISOPE, Vol.3, pp.784-791.

Mitsuyasu, H. and T. Kusaba. 1984. Drag coefficient over water surface under the action of strong wind, Journal of Natural Disaster Science, Vol.6-2, pp.43-50.

Mitsuta, Y. and T. Fujii. 1987. Analysis and synthesis of typhoon wind pattern over Japan, Bulletin Disaster Prevention Research Institute, Kyoto University, Vol.37, Part 4, No.329, pp.169-185.

Myers, V.A. and W. Malkin. 1961. Some properties of hurricane wind fields as deduced from trajectories, United States Weather Bureau, National Hurricane Research Project, Report 49.

Nonaka, H., M. Yamaguchi, Y. Hatada and Y. Itoh. 2000. A system for estimating extremes of wave height using an extended stochastic typhoon model, Proceedings of Coastal Engineering, JSCE, vol.47, pp.271-275, in Japanese.

Oouchi, K., J. Yoshimura, H. Yoshimura, R. Mizuta, S. Kusunoki, and A. Noda. 2006. Tropical cyclone climatology in a global-warming climate as simulated in a $20 \mathrm{~km}$-mesh global atmospheric model: frequency and wind intensity analyses, Journal of the Meteorological Society of Japan, 842, pp.259-276.

Powell, M. D., P. J. Vickery and T. A. Reinhold. 2003. Reduced drag coefficient for high wind speeds in tropical cyclones, Nature, Vol.422.

Rumpf, J., E. Rauch, V. Schmidt and H. Weindl. 2006. Stochastic modeling of tropical cyclone track data, 27th Conference on Hurricanes and Tropical Meteorology, AMS, 5A-6.

Takahashi, S., H. Kawai and T. Takayama. 2002. Storm surge disaster by typhoon No.9918 performance design of coastal defense-, Proceedings of Solutions to Coastal Disasters Conference 2002, ASCE, San Diego, USA, pp 735-749.

Zhang, W., W. Perrie and W. Li. 2006. Impact of waves and sea spray on midlatitude storm structure and intensity, Monthly Weather Review, AMS, Vol. 134, pp.2418-2442. 